
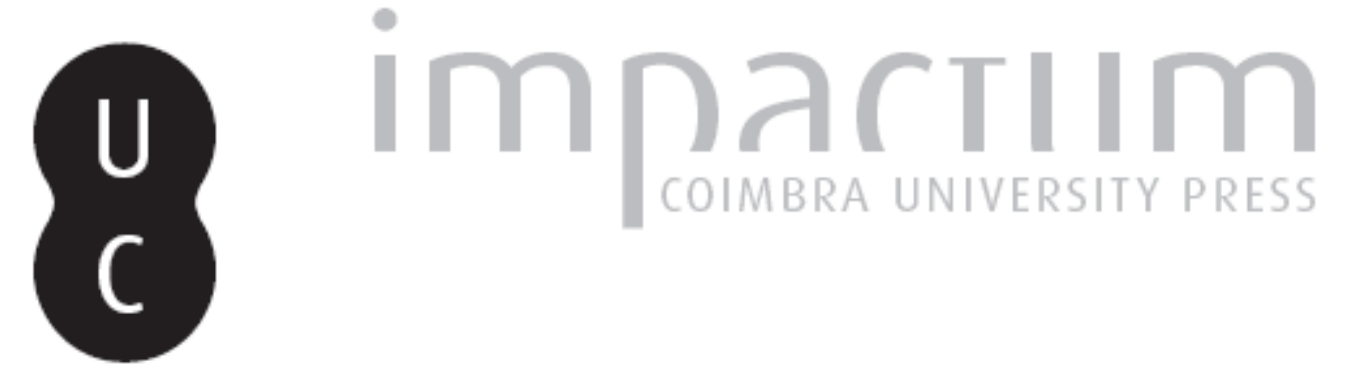

\title{
Catolicismo: fator de unidade
}

\section{Autor(es): $\quad$ Scarano, Julita}

Publicado por: Imprensa da Universidade de Coimbra

URL persistente:

URI:http://hdl.handle.net/10316.2/45317

DOI:

DOI:https://doi.org/10.14195/2183-8925_9-2_11

Accessed : $\quad$ 26-Apr-2023 13:22:54

A navegação consulta e descarregamento dos títulos inseridos nas Bibliotecas Digitais UC Digitalis, UC Pombalina e UC Impactum, pressupõem a aceitação plena e sem reservas dos Termos e Condições de Uso destas Bibliotecas Digitais, disponíveis em https://digitalis.uc.pt/pt-pt/termos.

Conforme exposto nos referidos Termos e Condições de Uso, o descarregamento de títulos de acesso restrito requer uma licença válida de autorização devendo o utilizador aceder ao(s) documento(s) a partir de um endereço de IP da instituição detentora da supramencionada licença.

Ao utilizador é apenas permitido o descarregamento para uso pessoal, pelo que o emprego do(s) título(s) descarregado(s) para outro fim, designadamente comercial, carece de autorização do respetivo autor ou editor da obra.

Na medida em que todas as obras da UC Digitalis se encontram protegidas pelo Código do Direito de Autor e Direitos Conexos e demais legislação aplicável, toda a cópia, parcial ou total, deste documento, nos casos em que é legalmente admitida, deverá conter ou fazer-se acompanhar por este aviso.

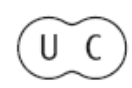


REVISTA DE HISTORIA DAS IDEIAS 9

\section{O SAGRADO E O PROFANO **}

HOMENAGEM A J. S. DA SILVA DIAS

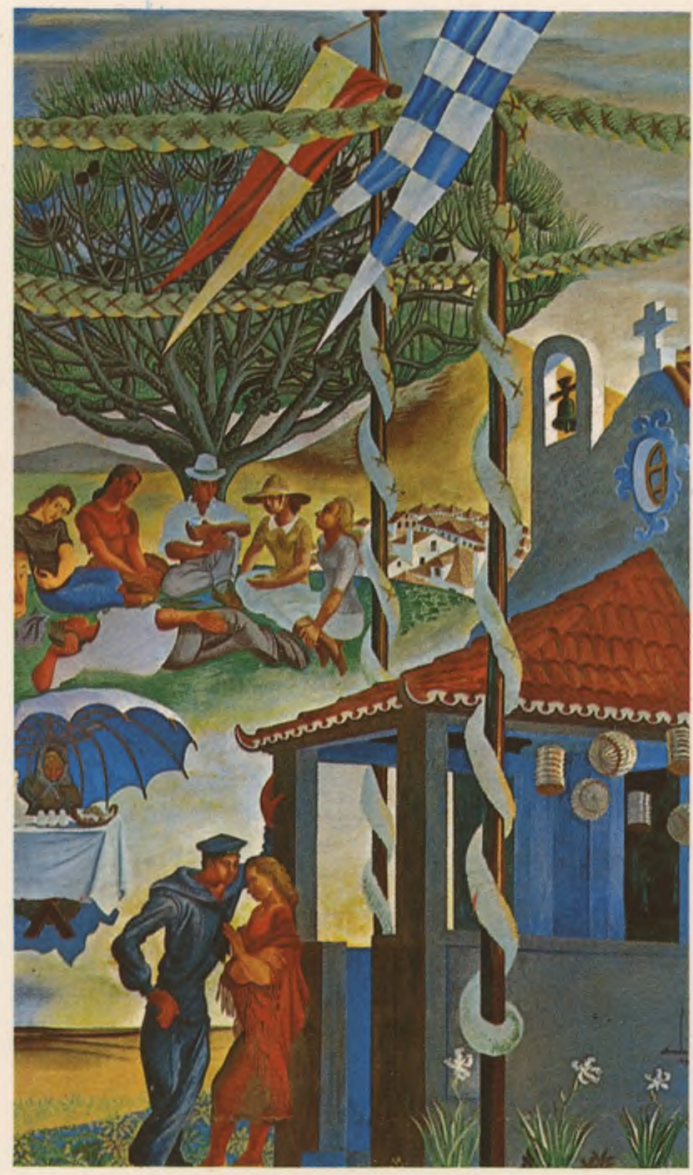

INSTITUTO DE HISTORIA E TEORIA DAS IDEIAS FACULDADE DE LETRAS 


\title{
CATOLICISMO, FATOR DE UNIDADE
}

\begin{abstract}
Alicerçada no catolicismo, religião dominante, a colonização da América espanhola e do Brasil apresentou aspectos complexos, não apenas os que se referiam ao mercantilismo, colonialismo e expansão marítima. A existência de uma religião de Estado traz implicações que abarcam as questões políticas, sociais e outras, em suma, o aspecto confessional apresenta variáveis que se cruzam com todas as demais.
\end{abstract}

No século XVIII, em terras brasileiras e americanas, a teologia era vista como fundamento da sociedade, e, ao menos idealmente, servia de suporte a todos os aspectos da vida das populações. Os princípios cristãos deveriam orientar a vida política e económica e mesmo os aspectos do quotidiano e, do nascimento à morte havia necessidade da ação da Igreja. Ela centralizava a vida dos livres e dos escravos e da Igreja emanavam todos os documentos necessários à vida civil.

Assim, a religião se toma partícipe do sistema colonial, parte integrante dele.

A existência de uma religião de Estado e sua consequente valorização levam os povos $\mathrm{e}$ as autoridades a tratarem com descaso todas as demais manifestações religiosas. Se, no aspecto religioso, domínio do sagrado, essa manifestação xenófoba é mais compreensível, de acordo com a mentalidade contra-reformista, é preciso não esquecer que tal mentalidade se espraia por todos os domínios da cultura. Qualquer manifestação dos grupos indígenas ou africanos era considerada discrepante e perigosa. Outras crenças e costumes eram, não

* Faculdade de Filosofia e Letras da Universidade de São Paulo. 
apenas desvalorizados, mas sujeitos a perseguições e a penas, desde aquelas pecuniárias às trazidas pela ação inquisitorial. Os judaizantes, talvez considerados mais aptos a atacar o sistema, gozando, inúmeros deles, de boa posição económica e social, constituiam o alvo mais conspícuo.

A posição marginal de quem não participasse da vida da Igreja já seria fator de impedimento para que florescessem outras religiões, mas isso era praticamente impossível, dada a estreita relação entre o eclesiástico e o temporal. $\mathrm{Na}$ época, aliás, raramente se deixava de ser exclusivista.

É preciso não esquecer que a xenofobia se estende a todo e qualquer aspecto e o período se caracteriza pela incompreensão do «outro», em sua maneira de ser e de viver, em suas crenças e costumes, questões, infelizmente, ainda não solucionadas em nossos dias.

Ninguém ignora que a união entre Igreja e Coroa, que fazia desta a representante do Reino celeste na terra, tomavam muito graves qualquer discrepância ou desvio religioso, capaz de perigosamente se refletir em rejeição a todo o sistema. A manutenção de outras crenças e diferentes práticas religiosas torna-se um crime extremamente grave, que deve ser controlado. Nos Compromissos de irmandades de pretos e de gente de cor, por exemplo, alguns bem pouco restritivos em relação a questões que a outros grupos pareciam graves, a «feitiçaria» é sempre terminantemente proibida e impede a entrada ou permanência na confraria $O$ ). Dá-se enfâse a esse aspecto com a finalidade de afastar totalmente de suas crenças tradicionais aqueles que desejavam integrar organizações católicas.

O cristianismo, por suas próprias características intrínsecas, foi exclusivista, desde os seus primórdios e, mesmo cedendo ou absorvendo inúmeros aspectos de outras religiões e crenças com as quais manteve contacto, fixou determinados pontos como não passíveis de mudanças. Daí a severidade com crenças trazidas na bagagem dos africanos, mesmo que, nem sempre essa vigilância tivesse dado resultados. Segundo Roger Bastide, por exemplo, as irmandades católicas constituíram fócos de manutenção da religiosidade típica africana, ocultando-a com a face da ortodoxia $\left({ }^{2}\right)$.

O Julita Scarano, Devoção e Escravdião, 2. a ed., S. Paulo, Companhia Editora Nacional, Coleção Brasiliana, 1980.

$\left.{ }^{2}\right) \quad$ Roger Bastide, Les religions africaines au Brésil, Paris, Presses Universitaires de France, 1960. 
O religioso, não constitui, entretanto, o campo único do esforço português no sentido de manter a unidade do vasto continente do qual foi a Metrópole. Sempre, em todos os pontos de vista se buscou uma unidade e ortodoxia, capaz de pôr cobro à situação trazida pela forçada junção de elementos caóticos. São os grupos indígenas, paulatinamente dizimados ou afastados pela ação do povoamento e também os africanos, jogados em lugares onde chegava a ambição e o homem branco. Tantas «nações» diferentes, além dos elementos européus, teriam que ser polidas e amalgamadas no ponto de vista religioso e político. Quanto à miscigenação propriamente dita, esta se processava, com ou sem apoio das autoridades eclesiásticas e civis.

Nas áreas de mineração, por exemplo, onde o povoamento português se processou apenas no fim do século XVII e sobretudo no XVIII, essas questões se colocaram com intensidade maior.

A rapidez da ocupação territorial, o afluxo espontâneo de tantos aventureiros que com seus escravos vinham em busca de uma riqueza rápida foram de molde a tumultuar $o$ povoamento que se processava de maneira mais contida e gradual em outros pontos do território, sobretudo em suas áreas litorâneas. Desse modo, as terras de mineração constituem exemplos significativos do esforço reinol no sentido de buscar unidade e ortodoxia, em todos os aspectos da vida colonial.

Difícil é definir até que ponto as regras que se estabeleceram ou se procurou estabelecer encontram eco e resposta no seio da população. É praticamente impossível determinar o quantum de aceitação de crenças e de idéias, de conceitos e de categorias que se encontrava em habitantes de um determinado local em um momento dado. Também interessante seria verificar a acomodação entre $o$ ideal que se estabelece e aquilo que será possível obter, em suma como as populações reagiram em face às regras trazidas pela religião católica contra-reformista.

É preciso não esquecer que os preceitos católicos vieram como imposição do colonizador que trazia sua crença como parte de um sistema global que visava a grandeza da Coroa. As imposições da autoridade civil não deixavam de influenciar nas questões religiosas, uma vez que na prática, o eclesiástico e o leigo constituiam um todo único.

$\mathrm{O}$ catolicismo na América oferecia peculiaridades próprias, trazidas por inúmeros fatores dos quais a escravidão foi uma das mais significativas, ou mesmo, a mais significativa. 
Por tal razão, houve necessidade de adaptar determinadas regras européias a um meio tão peculiar. Essa constituiu a finalidade de reuniões e dos Sínodos, que tiveram lugar em alguns pontos da América espanhola. Desde os inícios do século XVII eles tiveram lugar, como o dos Dominicanos em 1622 que serviu de modelo para o Sínodo da Bahia em 1707.

É interessante notar que o Sínodo brasileiro foi convocado nos inícios do século XVIII, tantos anos depois daqueles reunidos na América espanhola, cujos postulados vinham sendo seguidos em nossa terra. Essa convocação que partiu do Arcebispado da Bahia, na pessoa do $5 .^{\circ}$ arcebispo daquele Arcebispado, D. Sebastião Monteiro da Vide tem lugar em um momento em que se processa violenta expansão territorial, ocupação de novos territórios, com o encontro de novos grupos indígenas, bem como a chegada de outros escravos africanos. Sem dúvida, foi sentida a necessidade de uma recolocação de valores, de uma reavaliação e também de um desejo de estabelecer regras precisas e firmar determinados pontos vistos como essenciais.

Interessante é conhecer que o Arcebispo que convocou o Sínodo de seu Arcebispado, do qual resultaram as chamadas Constituições Primeiras do Arcebispado da Bahia (3), utilizadas em todo o Brasil foi jesuíta e militar, antes de estudar Direito Canónico em Coimbra e finalmente tomar ordens e ser elevado a inúmeras dignidades. Ele, explicando as razões que o levaram a reunir um Sínodo com a finalidade de elaborar diretrizes para a vida eclesiástica e religiosa, bem como pastoral, neste continente, mostra que as regras emanadas de Lisboa não serviam a uma terra nova, diferente da Europa em inúmeros aspectos, conforme foi acima assinalado. Reunido desde 1702, quando da chegada do Arcebispo, a obra foi dada por concluída em 1707 e publicada em 1719 e em 1720.

$\mathrm{O}$ intuito é exatamente aquele de coibir qualquer modificação ou interpretação dúbia dos princípios tridentinos, conforme se depreende das palavras de D. Sebastião a todos os religiosos da Arquidiocese, explicando que sempre que houver necessidade de interpretação «a reservamos a Nós».

Essas Constituições mostram, antes de outra qualquer consideração, uma visão de mundo totalmente ordenada e contida em regras estabelecidas, com nítida separação entre o

(3) Sebastião Monteiro da Vide, Constituições do Arcebispado da Bahia aprovadas no Sinodo de 1707, S. Paulo, Typographia 2 de Dezembro, 1853. 
Bem e o Mal, sem deixar espaço para dúvidas. Diferem nesse aspecto das características apresentadas pela religiosidade atual, mais aberta, ao menos até há alguns anos atrás, possibilitando o aparecimento de variadas vertentes, sem, evidentemente, quebrar a unidade do catolicismo.

Esse aspecto dogmático, entretanto, não impede que a obra se baseie em um princípio de realidade, no sentido de que procura se adaptar às circunstâncias locais e aos limites do possível, segundo a mente do Arcebispo e dos demais organizadores. E certo que constitui uma manifestação de ortodoxia. Além de dirimir dúvidas, sua meta é coibir abusos.

Toda a organização do sistema, a completa exclusão de outras religiões e de outras culturas dão a impressão de que o Reino português era visto como a encarnação do Reino Celeste e que os representantes da hierarquia religiosa estavam capacitados a perceber claramente «o pensamento de Deus» e tinham necessidade de pô-lo em prática. Ao mesmo tempo, no ponto de vista prático a meta é manter a coesão interna da Colónia, com a manutenção de uma unidade que abrange o campo político, económico e social, além do modus vivendi, todos os aspectos em forte coesão com aquele religioso.

Respondendo às necessidades da época, as Constituições, mesmo tendo sido elaboradas sob a chancela do Episcopado da Bahia, sem a participação geral, conforme sua primeira intenção, foram aceites e seguidas em todo o Brasil, tendo sofrido algumas modificações apenas sob a ação das «Leis do Império». De fato, as Constituições pautaram a organização religiosa do país no decorrer do século XVIII e XIX, até à República.

A obra trata, de maneira exaustiva e minuciosa, de aspectos doutrinais e de questões práticas. Com a finalidade de manter a unidade, explicita e regulamenta o que se deveria crer e também não esquece aquilo que era preciso praticar. Buscando impedir que fatores estranhos e costumes alienígenos conspurcassem a pureza da doutrina e do culto, tudo é regulamentado, mesmo questões de pormenores. De resto, nesse aspecto, não é original, seguindo a maneira de ser daqueles momentos históricos. Interessante é notar que um dos aspectos focais dessas regras ordenadas para o Brasil trata de problemas referentes ao escravo, ou melhor da escravidão em face ao catolicismo.

A escravidão é tratada com naturalidade, não se vê colocada em questão e não se discute sua validade e moralidade. Pelo contrário, mostra-se como um dever o ser-se «um bom senhor», sem questionar a moralidade da existência do senhor 
e do escravo. É uma aceitação da época e da situação vigente e, do mesmo modo que se menciona a necessidade de agir de maneira justa e caridosa em relação ao escravo, não permanecem nas sombras os deveres atribuídos aos escravos, sem lhes abrir qualquer possibilidade de contestação. Se, de um lado é aceite a humanidade do escravo que deve buscar sua salvação individual por meio dos mesmos sacramentos, não se vislumbra ação condenatoria do sistema escravista em si.

Um Título à parte (LXXI) foi reservado nas Constituições ao Casamento dos Escravos, que mostra a ambiguidade e o duplo aspecto corn que era tratada a questão, oscilando entre a aceitação do poder do senhor (....E declaramos, que posto que casem, ficão escravos como antes erão, e obrigados a todo o serviço de seu senhor), e a instigação para que tais senhores não impeçam ou dificultem o matrimonio dos cativos ou «o uso delle». Essas obrigações são sob pena de pecado mortal, o que mostra a gravidade com que a questão era encarada, mas também a dificuldade em fazer seguir essas regras, mais ainda em lugares isolados.

Quanto ao matrimonio, há, segundo a Igreja, valorização apenas do sacramento, de modo a não impedir que escravos unidos anteriormente, segundo outros sistemas, sejam dispensados, podendo receber o sacramento, depois disso.

Nesse, como em outros aspectos, a questão do escravo padece da mesma ambiguidade; é aceite como um ser humano, embora considerado «rude», algumas vezes, mas sujeito a jugo que o impede de usufruir de sua humanidade. Quanto ao aspecto da «brutalidade», ou «boçalidade» mencionada no livro, busca-se simplificar, melhor dizendo, infantilizar a doutrina a fim de que possa ser compreendida, segundo o conceito que norteou sua elaboração. Essa infantilização faz com que, em documentos emanados por religiosos, o homem de cor algumas vezes é mencionado como «pretinho» e mesmo «os pobres pretinhos». O interessante é que, o próprio preto, buscando tirar proveito dessa «benevolência», em documentos ou cartas que fazem pedidos, usam conceitos semelhantes a seu próprio respeito.

Em relação à «humanidade» do preto, que o torna merecedor da salvação, há reiterados avisos aos senhores de que pecam se mantém na ignorância da doutrina, ou impedem, de algum modo a sua prática a seus escravos. Reitera-se que Deus está acima do senhor e, diante da divindidade, todos os 
seres humanos são iguais $\left(^{4}\right)$. Essa questão é vista como de extrema gravidade, se bem que, certamente tal não sucedeu na prática. A conversão se coloca também acima do pátrio poder, no sentido que os donos de escravos menores de 7 anos devam instruí-los, mesmo contra a vontade de seus pais. O mais significativo, entretanto é que os escravos só possam alcançar o batismo dando seu consentimento, mesmo que tenham entre 7 e 12 anos. Esse aspecto, me parece a cabal confirmação de serem eles equiparados aos demais elementos da população, por mais que estejam sujeitos a cativeiro.

Todos esses aspectos manifestam a ambiguidade com que era tratada a escravidão e a própria pessoa do escravo pelo catolicismo dominante e sem dúvida, na prática, tais questões apresentavam inúmeros problemas resolvidos no âmbito individual, ora apelando para a benevolência, ora para o rigor, dependendo de pessoas e de circunstâncias. Sem dúvida há a busca de uma harmonização, desejo de, ao mesmo tempo explorar economicamente o escravo e lhe propiciar a salvação e cristianizá-lo. Essas tendências antagónicas e, na prática excludentes, marcam $\mathrm{o}$ aspecto religioso da escravidão e se manifestam com grande agudeza em todo o período colonial, sobretudo no século XVIII, uma vez que a mineração e o rápido povoamento territorial são propícios ao exacerbamento de situações.

O desejo de estabelecer uma unidade, tanto no sentido religioso, como no político, que, aliás, formavam um todo e se confundiam em inúmeros aspectos práticos, encontrava certas dificuldades, das quais a escravidão era das mais conspícuas. Isso levava a acomodações, à procura de um equilíbrio nem sempre possível, mas ardentemente almejado. De resto, esses aspectos se coadunavam perfeitamente com o catolicismo contra-reformista, vigente no período.

(4) Na prática, essa afirmação se vê continuamente reiterada nas canas, exortações, visitas pastorais, etc., ou seja, nas manifestações das autoridades eclesiásticas. 